\section{BY THE NUMBERS} Tennessee

\section{BY LAURA CASSIDAY}

$\mathrm{K}$ nown to music lovers as the capital of country and a birthplace of the blues, Tennessee has a history of creativity - and not just in music. In 1943, more than a decade before Elvis Presley entered a Memphis studio to record his first hit, some of the greatest scientists of the twentieth century converged in secret in the hills of Oak Ridge, Tennessee, to develop the atomic bomb. One of four major sites of the Manhattan Project, the Oak Ridge facility harnessed the abundant hydroelectric power of the Tennessee Valley Authority to enrich uranium for weapons. Now the research focus of Oak Ridge National Laboratory has shifted from weapons development to a variety of other energy-related topics. Bioscience is also burgeoning in the state, which is home to several major universities including Vanderbilt University in Nashville and five campuses of the University of Tennessee, as well as the world-renowned St Jude Children's Research Hospital in Memphis.

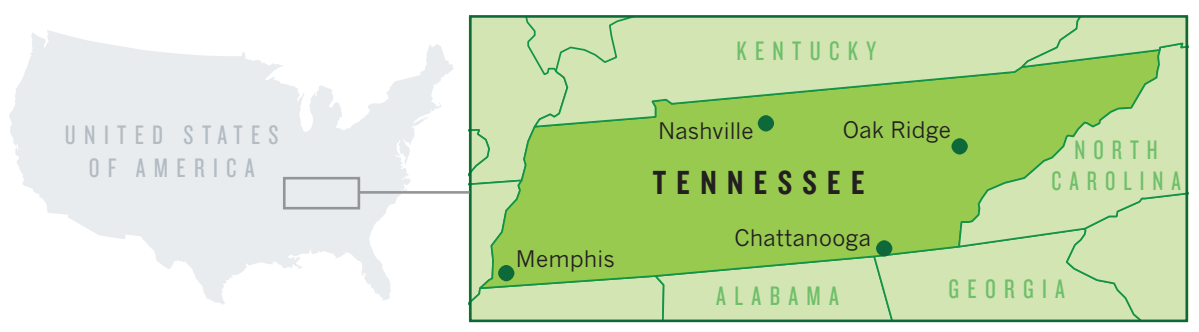

\section{DRUG AND PHARMACEUTICAL SECTOR}

- In 2008, 738 bioscience firms were registered in Tennessee. Of these, 27 specialized in pharmaceuticals, 46 in feedstock and chemicals, 268 in medical equipment and 397 in research and medical laboratories.

- In 2009, the University of Tennessee (UT) issued 17 technology licences to firms including GTx, a start-up in Memphis with roots at the UT Health Science Center. That year, 546 clinical trials were begun in the state. Of those now under way, 182 are for cancer treatments, 133 for heart disease and 105 for neurological disorders.

\section{BIOSCIENCE-RELATED OCCUPATIONAL EMPLOYMENT IN TENNESSEE, 2008}

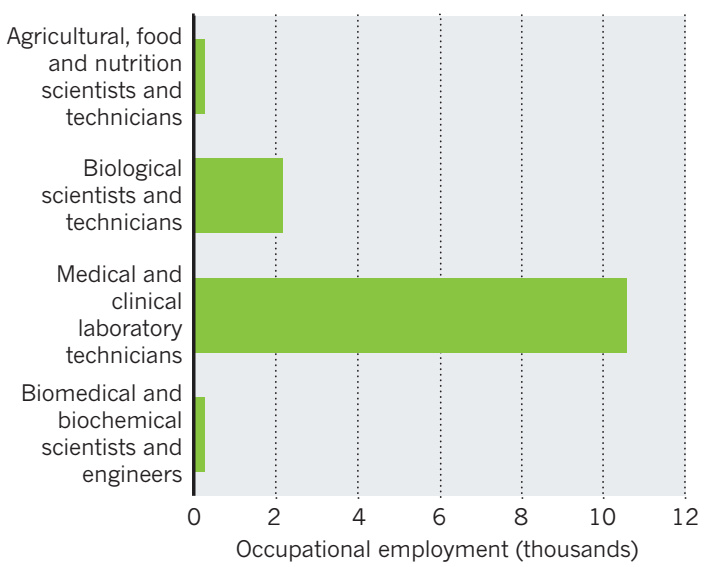

\section{RESEARCH AND ACADEMIA}

- In 2007, Vanderbilt University ranked tenth among US medical schools for National Institutes of Health funding, with a portfolio of US\$282.3 million.

- St Jude Children's Research Hospital was named the nation's top children's cancer hospital for 2010-11 by U.S. News \& World Report. Of its 205 faculty members, 126 are designated as 'research' and 79 as 'clinical', although many clinicians also conduct research.

- Oak Ridge National Laboratory has more than 4,800 staff, including $1,000 \mathrm{PhD}$ researchers and almost 1,000 postdocs, students and technicians. With annual funding of more than $\$ 1.65$ billion, the Department of Energy facility works in six areas: neutron science, energy, computing, systems biology, materials science and national security.

\section{BUSINESS AND COMMERCE}

- In 2008, the bioscience industry in Tennessee employed 25,717 people, an increase of 25.7\% since 2001. Workers in the industry had an average annual wage of $\$ 69,534$

- The UT-Baptist Research Park, a \$450-million project under construction in Memphis, will provide 130,000 square metres of space for bioscience research, education and business, and will generate 5,000 jobs.

- Graceland, Elvis Presley's former estate in Memphis, welcomes more than 600,000 tourists annually, making it one of the most visited private homes in the United States (after the White House).

\section{Q\&A Thomas Mason}

\author{
The director \\ of the Oak \\ Ridge National \\ Laboratory \\ (ORNL) discusses \\ Tennessee's \\ opportunities \\ and challenges.
}

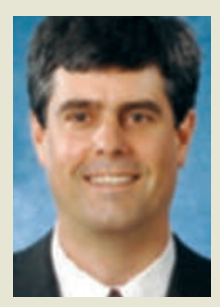

What are the best and worst things about working at the ORNL?

Our strength is our large scale. We have big facilities, such as the Spallation Neutron Source and the National Leadership Computing Facility. We tackle problems with teams of people from different disciplines. But there is bureaucracy with anything this large and complicated. You have more management and less autonomy than a researcher in academia. The challenge is to not get overwhelmed.

Who is most needed at the ORNL? We want a range of skills, from fundamental to applied research. We've been hiring everyone from established researchers to postdocs and people starting their careers.

\section{Are opportunities growing?}

In the past year, the ORNL has hired about 250 researchers, driven by growth in our big programmes, such as high-performance computing and our neutron facilities, and employee turnover. There are a lot of people who joined in the 1970s, and many are becoming eligible for retirement.

What are the pros and cons of being a scientist in Tennessee? After the Second World War, there was a debate about whether to keep a lab here. One side said there had been a huge investment, with the world's first research nuclear reactor, and we needed to use it. The other said people came here during the war but would want to go home. But the ORNL was started, and the isolation of the 1940s is less relevant now because we have the Internet and air travel. We have advantages here in cost of living and quality of life. It is less crowded. There are lakes and rivers and mountains. For people who are starting their careers and raising families, there is a lot to like. L.C. 